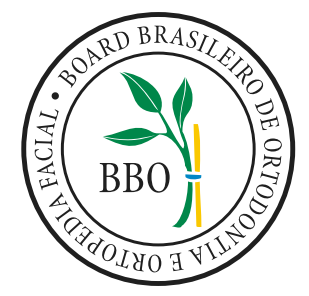

\title{
Má oclusão Classe II de Angle tratada sem extrações e com controle de crescimento*
}

\author{
Flávia Artese**
}

\section{Resumo}

A má oclusão Classe II de Angle é caracterizada por uma discrepância dentária anteroposterior, que geralmente está acompanhada por alterações esqueléticas. $\mathrm{O}$ tratamento ortodôntico precoce permite a correção da discrepância esquelética por controle de crescimento (primeira fase), o que favorece a correção do posicionamento dentário, mais tardiamente (segunda fase). Este relato descreve o tratamento de um caso de má oclusão Classe II, divisão 2, de Angle, em duas fases, e foi apresentado à Diretoria do Board Brasileiro de Ortodontia e Ortopedia Facial (BBO), como parte dos requisitos para a obtenção do título de Diplomado pelo BBO. O caso foi avaliado como representante da Categoria 1, ou seja, má oclusão Classe II de Angle tratada sem extrações dentárias e com controle de crescimento.

Palavras-chave: Má oclusão Classe II de Angle. Ortodontia Interceptativa. Ortodontia Corretiva.

\section{HISTÓRIA E ETIOLOGIA}

A paciente, leucoderma, do gênero feminino, apresentou-se para exame ortodôntico inicial aos 10 anos e 5 meses de idade. Tinha bom estado geral de saúde e não relatou histórico de doenças graves ou traumas. Também não apresentava hábitos de sucção ou postural, e possuía deglutição e fonação normais.

Estava em fase de dentadura mista e apresentava coroas de aço em alguns molares decíduos, além de desgastes nas faces proximais dos caninos decíduos superiores e inferiores, realizados, provavelmente, com o intuito de reduzir o apinhamento anterior (Fig. 1, 2). Esses procedimentos foram realizados por outro profissional, antes de sua consulta ortodôntica inicial. Não possuía queixa principal, tendo procurado tratamento por indicação profissional, e não tinha utilizado qualquer tipo de aparelho ortodôntico anteriormente.

\section{DIAGNÓSTICO}

Apresentava a face sem assimetria significativa, com perfil harmonioso e bom selamento labial passivo. Os terços facias eram proporcionais e a linha de sorriso normal (Fig. 1).

$\mathrm{Na}$ avaliação cefalométrica, observou-se padrão esquelético de Classe II, com ANB igual a 5 graus, devido à retrusão mandibular $\left(\mathrm{SNB}=75^{\circ}\right)$. No entanto, considerando-se os valores do ângulo SN-GoGn $\left(32^{\circ}\right)$, pôde-se inferir que a paciente teria um padrão de crescimento mandibular favorável, tanto no sentido horizontal quanto vertical.

* Relato de caso clínico, categoria 1, aprovado pelo Board Brasileiro de Ortodontia e Ortopedia Facial (BBO).

** Doutora e Mestre em Ortodontia pela UFRJ. Professora Adjunta de Ortodontia da UERJ. Diplomada pelo Board Brasileiro de Ortodontia e Ortopedia Facial. 

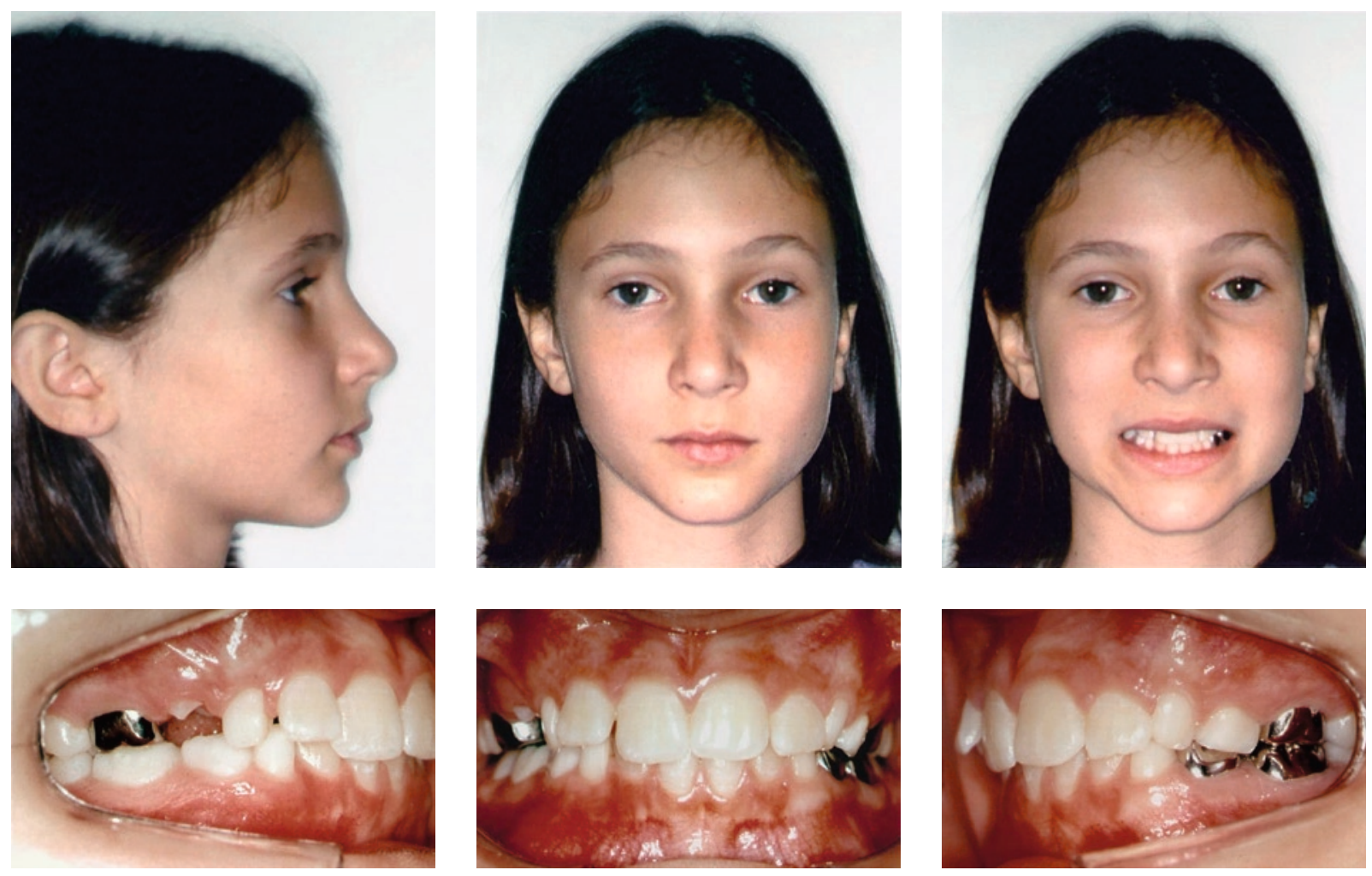

FIGURA 1 - Fotografias faciais e intrabucais iniciais.
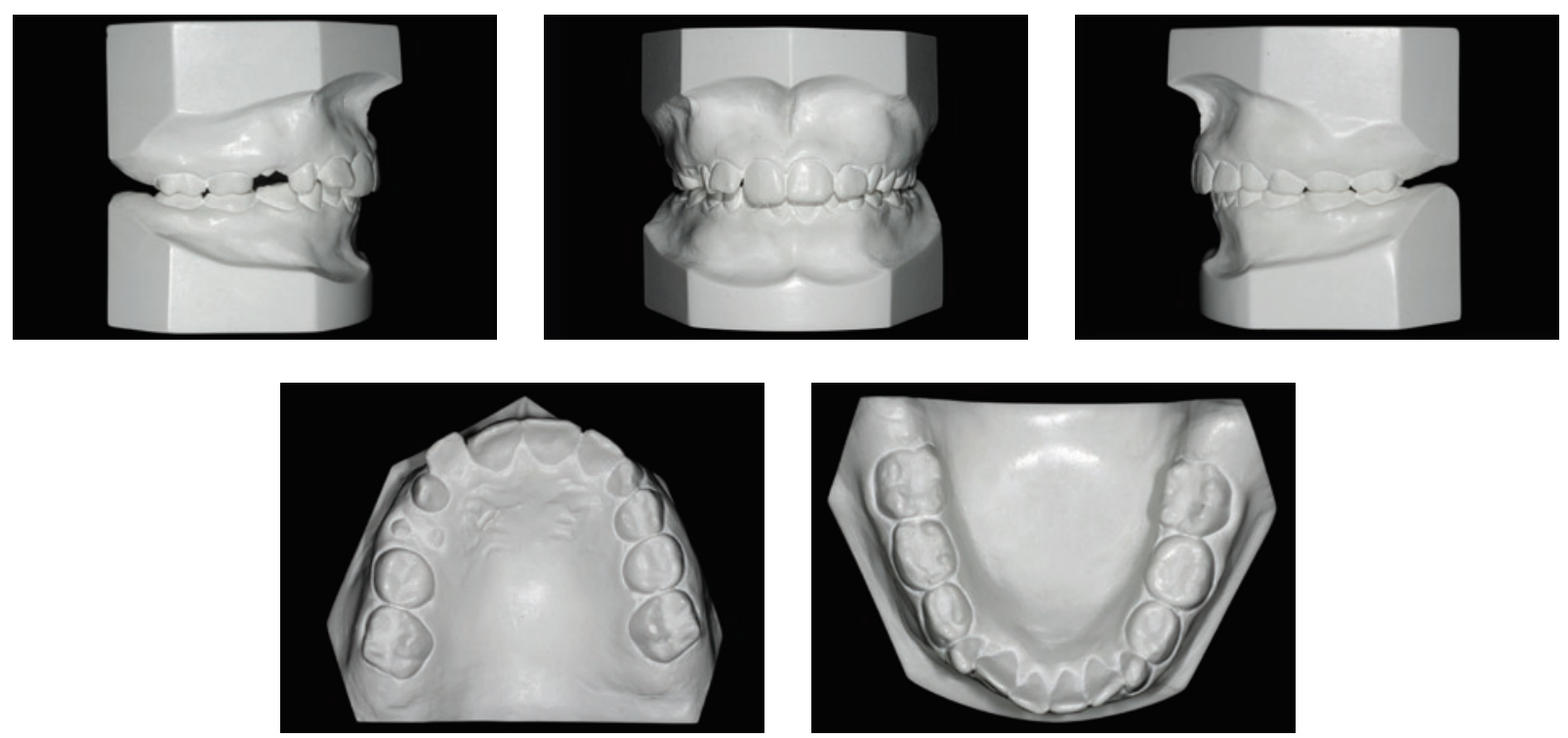

FIGURA 2 - Modelos iniciais. 
Quanto ao aspecto dentário, verificou-se que os incisivos superiores se apresentavam bastante verticalizados $\left(1-\mathrm{NA}=13^{\circ}\right)$, enquanto os inferiores estavam levemente inclinados para vestibular $\left(1-\mathrm{NB}=28^{\circ}\right.$ e IMPA $\left.=98^{\circ}\right)($ Tab. 1$)$.

A paciente estava em fase de dentadura mista e possuía má oclusão Classe II, divisão 2, de Angle, sobremordida de $4 \mathrm{~mm}$ e sobressaliência de $3 \mathrm{~mm}$ (Fig. 1, 2). Em manipulação mandibular, não apresentava desvios funcionais da posição de relação cêntrica para a de oclusão cêntrica. Possuía apinhamento anterior moderado, no arco superior, e leve, no inferior, com a linha média superior

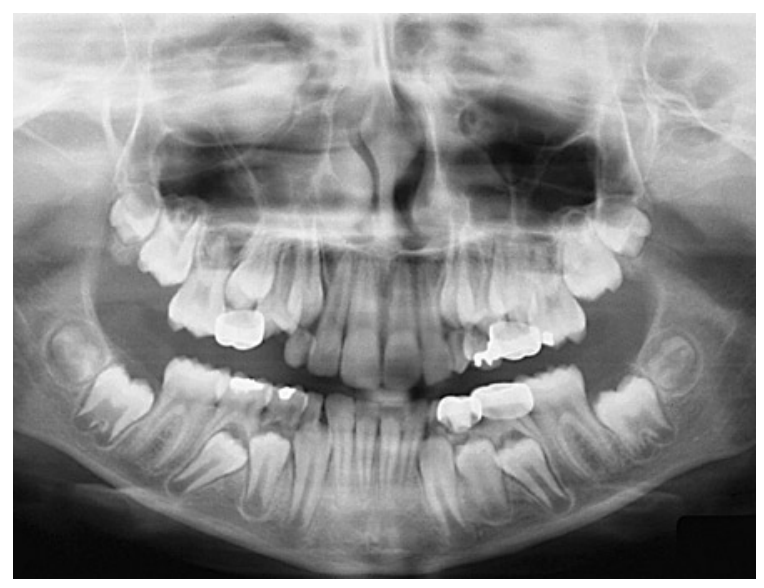

FIGURA 3 - Radiografia panorâmica inicial. desviada $1 \mathrm{~mm}$ para a direita (Fig. 1, 2).

$\mathrm{Na}$ análise das radiografias panorâmica, periapicais e interproximais (Fig. 3, 4), foi possível verificar a presença de todos os dentes permanentes, incluindo os terceiros molares, além dos caninos e molares decíduos, que ainda se encontravam na cavidade bucal. Todos os molares decíduos apresentavam restaurações, sendo algumas dessas coroas de aço.

Como pode ser observado na radiografia de mão e punho (Fig. 5), a paciente se encontrava em fase inicial do surto de crescimento puberal, caracterizada pelo aparecimento do osso sesamoide e pelo início do capeamento das diáfises.

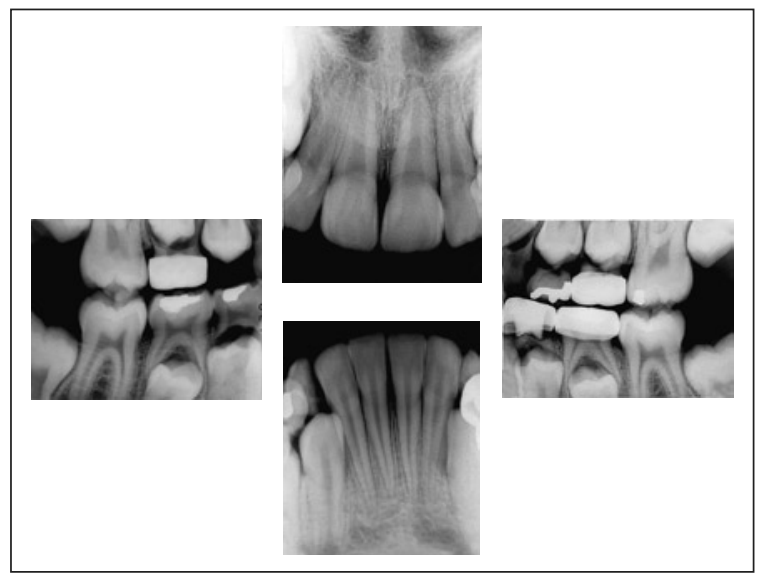

FIGURA 4 - Radiografias periapicais dos incisivos superiores e inferiores e interproximais dos lados direito e esquerdo iniciais.

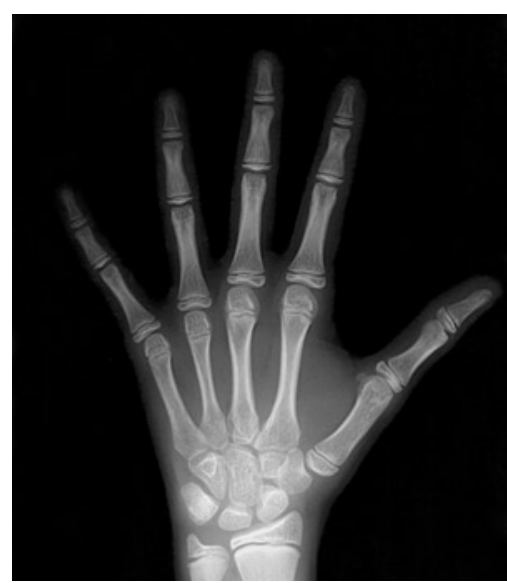

FIGURA 5 - Radiografia de mão e punho inicial.
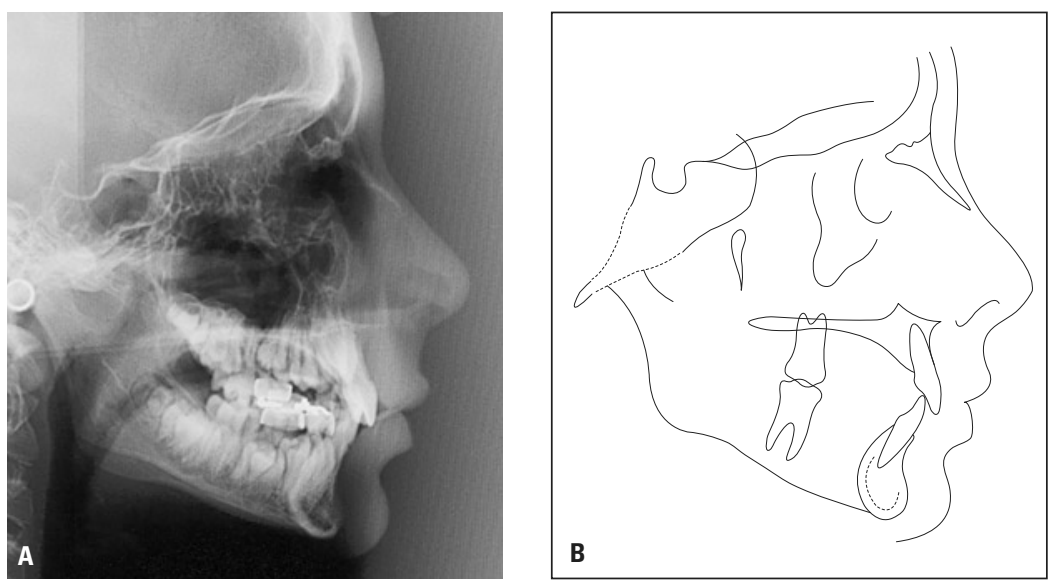

FIGURA 6 - Radiografia cefalométrica de perfil (A) e traçado cefalométrico (B) iniciais. 


\section{OBJETIVOS DO TRATAMENTO}

Os objetivos do tratamento incluíram reduzir a discrepância esquelética anteroposterior, por redirecionamento do crescimento maxilar, enquanto se permitia o crescimento normal da mandíbula, além de manter a relação transversa dos arcos.

O estabelecimento da relação de chave de oclusão nos molares, a obtenção de espaço para correção dos apinhamentos na região anterior e a redução da sobressaliência também foram almejados. Em relação à sobremordida, o desenvolvimento normal da oclusão, com o crescimento alveolar posterior, promoveria sua leve e necessária redução.

No aspecto facial, visou-se a melhora do perfil e a manutenção das proporções faciais, assim como da linha de sorriso.

\section{PLANO DE TRATAMENTO ( $1^{\text {a }}$ FASE)}

$\mathrm{Na}$ primeira fase do tratamento, planejou-se a correção da discrepância esquelética, através do redirecionamento do crescimento maxilar, utilizando-se aparelho extrabucal de Kloehn, com 360g de força por lado. Propôs-se, também, a utilização de um aparelho lip bumper, para a manutenção do comprimento do arco inferior. Ambos os aparelhos deveriam ser usados de maneira intensiva, de 14 a 24 horas por dia.

\section{Progresso do tratamento}

Para a instalação do aparelho extrabucal de Kloehn e do lip bumper, foram cimentados anéis nos primeiros molares permanentes superiores e inferiores. Esses anéis já possuíam tubos de diâmetro 0,045 " e braquetes conversiveis. $\mathrm{O}$ aparelho extrabucal de Kloehn foi adaptado, tendo sido mensurada a força de $360 \mathrm{~g}$ por lado. O lip bumper foi instalado no arco inferior, com distância de, aproximadamente, $3 \mathrm{~mm}$ da face vestibular dos incisivos inferiores. A paciente foi instruída a usar ambos os aparelhos por um mínimo de 14 horas por dia. O uso inicial foi de duas horas, acrescendo-se duas horas a cada três dias, para garantir sua adaptação gradual ao tratamento.

A paciente foi acompanhada mensalmente e esta primeira fase teve duração de 21 meses. A utilização do lip bumper foi interrompida quando se observou a exfoliação de todos os dentes decíduos inferiores e a completa irrupção de seus sucessores permanentes. $\mathrm{O}$ aparelho extrabucal foi utilizado por mais tempo, até o estabelecimento da relação molar de chave de oclusão, quando novos exames foram solicitados para avaliação das modificações ocorridas até então (Fig. 7 - 11).

\section{Resultados obtidos}

Após análise desses exames, verificou-se que os objetivos propostos para a primeira fase do tratamento foram atingidos. Houve redução do ângulo ANB em 4 graus, ocorrida tanto pela restrição do crescimento anterior da maxila e movimento do ponto A para posterior, com a correção da inclinação dos incisivos superiores, quanto pelo crescimento mandibular. O plano mandibular permaneceu inalterado, tendo sido mantido o ângulo SN-GoGn em 32 graus (Tab. 1, Fig. 12). Os incisivos inferiores recolocaram-se 6 graus, enquanto os superiores inclinaram 12 graus, o que, associado a seu padrão de crescimento mandibular, tornou o perfil levemente côncavo (Fig. 12). Acredita-se que essas modificações ocorreram por efeito do aparelho extrabucal e pela presença de uma sobremordida bem estabelecida, uma vez que o lip bumper foi removido antes do extrabucal.

No aspecto dentário, houve extrusão e movimentação para distal dos molares superiores (Fig. 12B), o que permitiu a obtenção da relação molar de chave de oclusão. Os apinhamentos, na região anterior, foram corrigidos pelo aumento no comprimento do arco superior e pelo aproveitamento do leeway space, no arco inferior. No arco superior, devido à excelente colaboração da paciente quanto ao uso do aparelho extrabucal de Kloehn, pode-se observar, inclusive, a presença de espaços generalizados (Fig. 7, 8). 

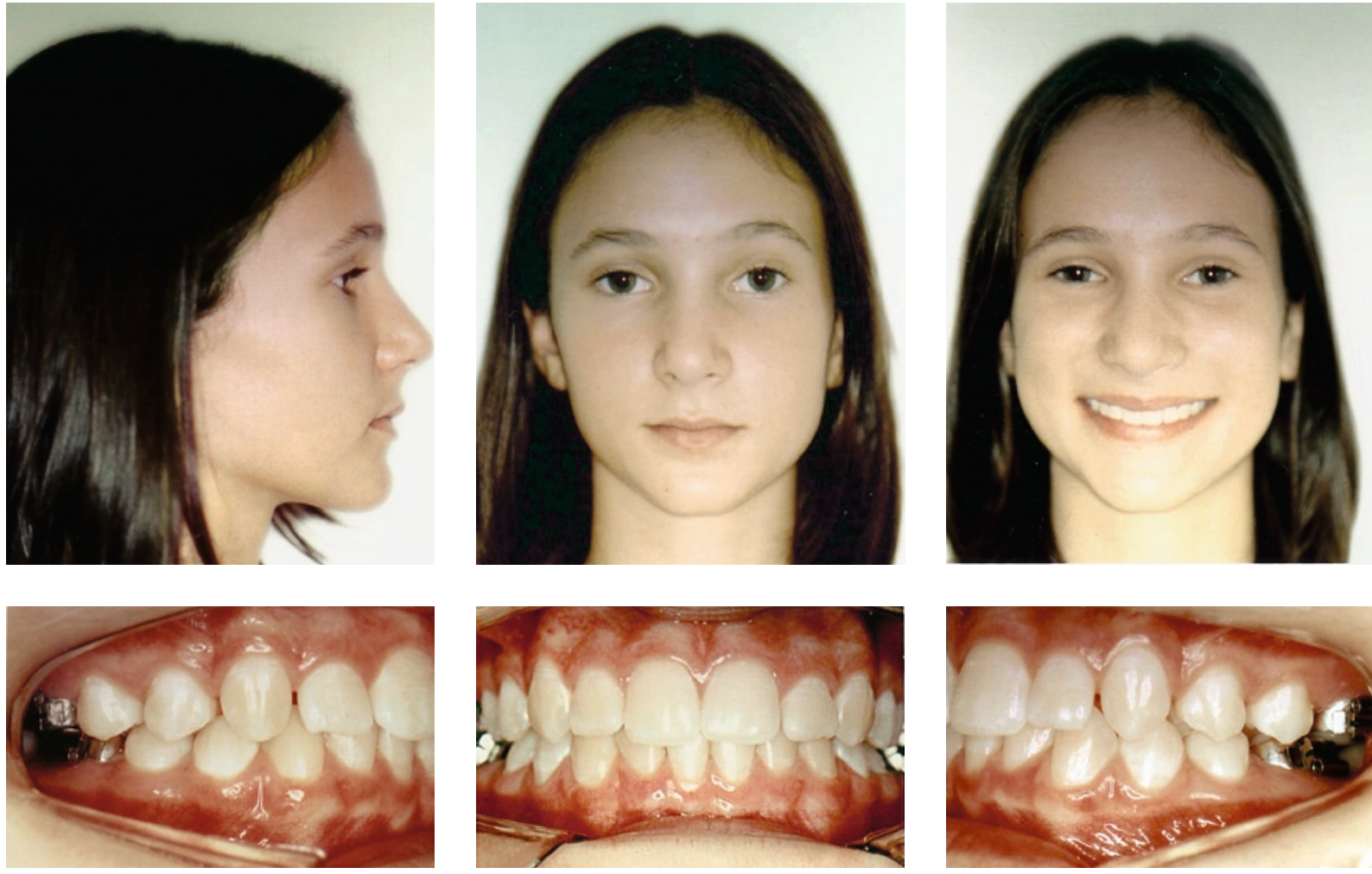

FIGURA 7 - Fotografias faciais e intrabucais intermediárias.
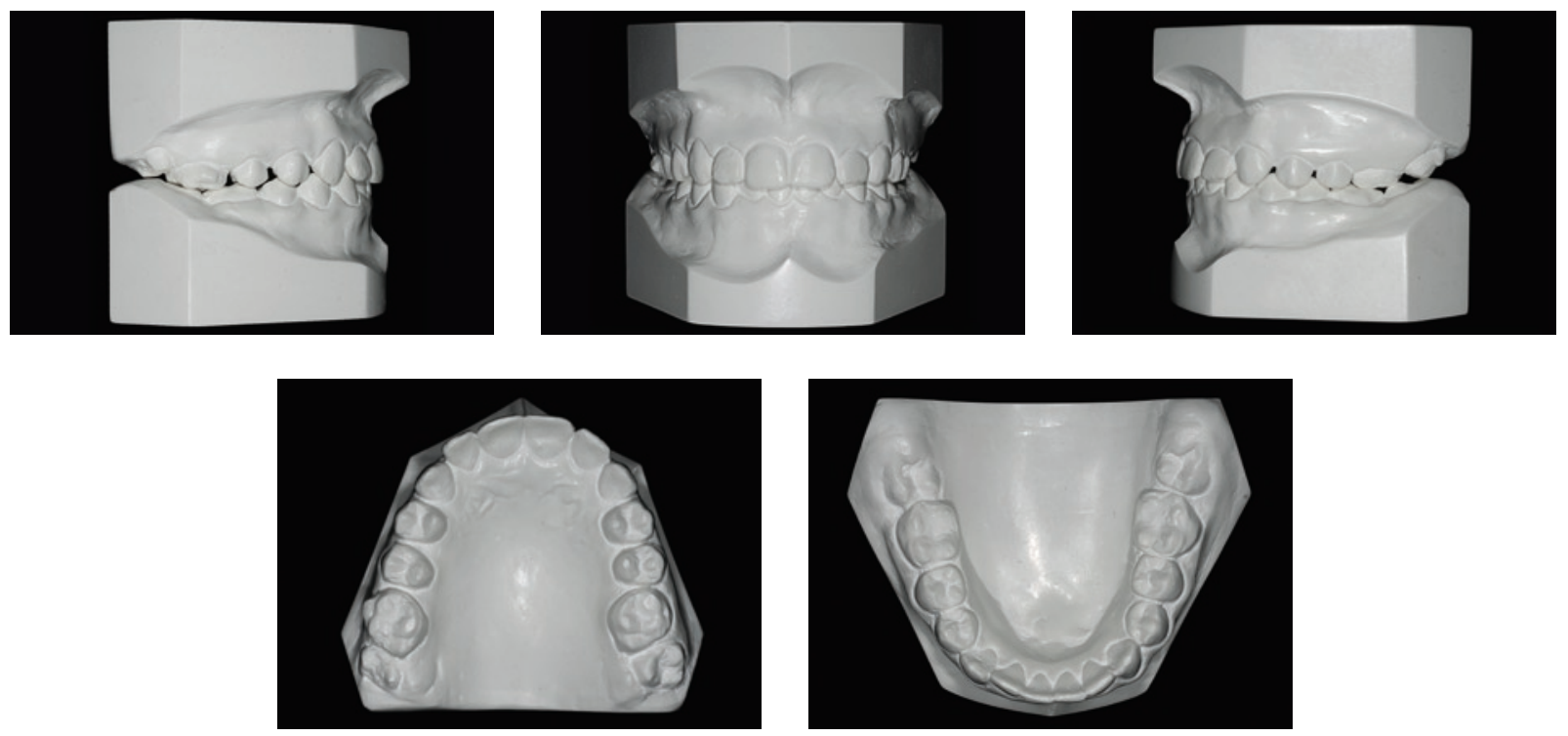

FIGURA 8 - Modelos intermediários. 


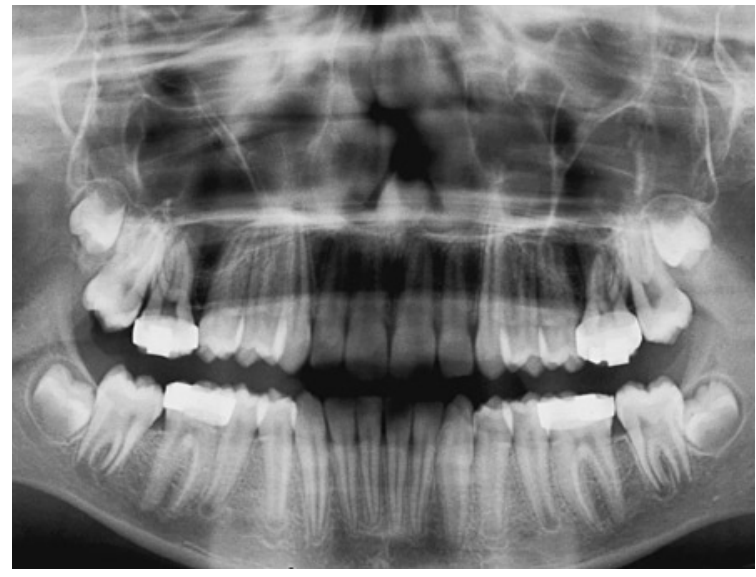

FIGURA 9 - Radiografia panorâmica intermediária.
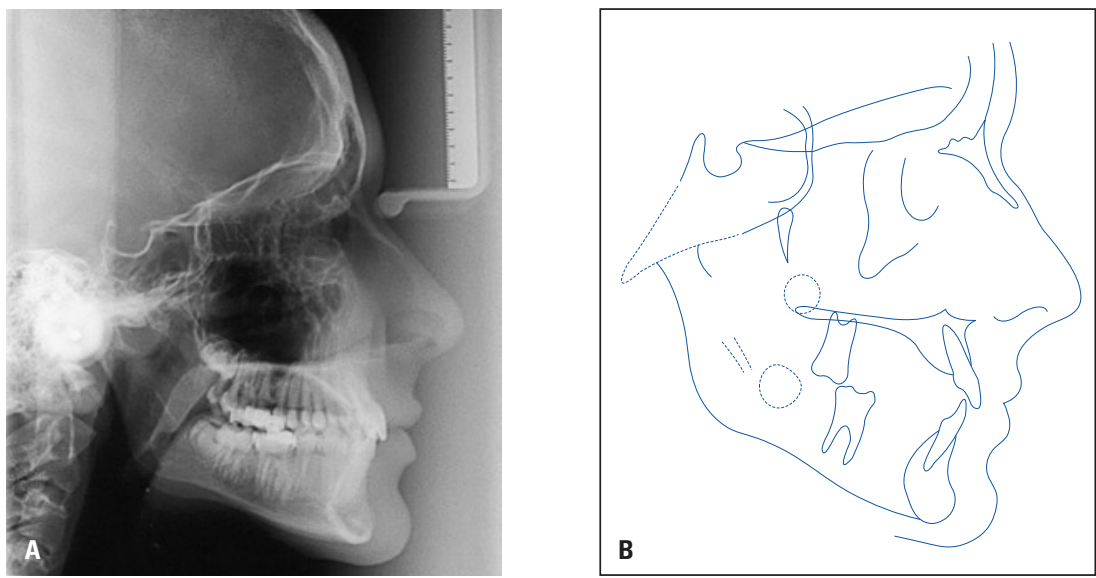

FIGURA 11 - Radiografia cefalométrica de perfil (A) e traçado cefalométrico (B) intermediários.
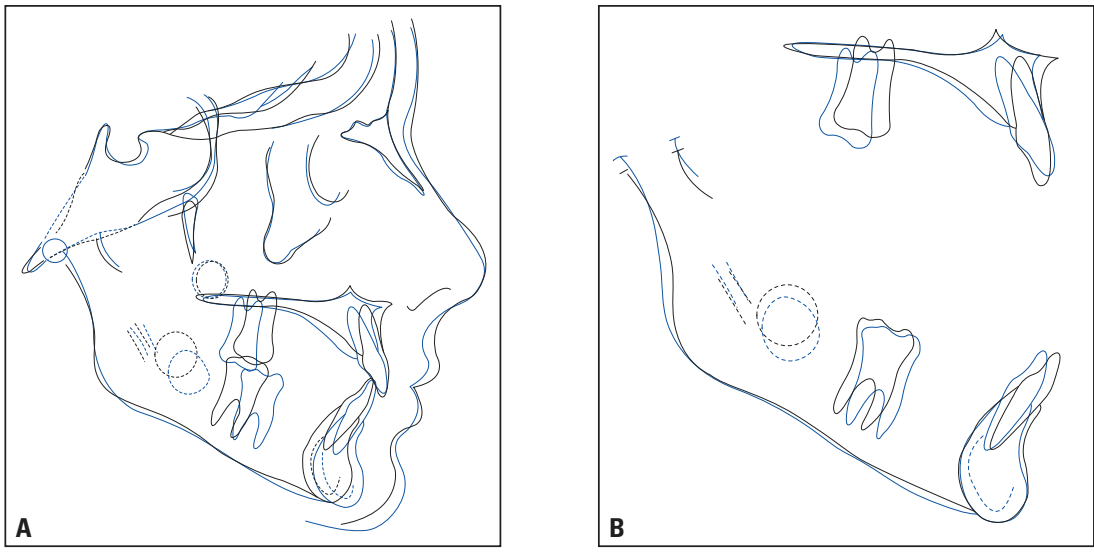

FIGURA 12 - Sobreposições total e parciais dos traçados cefalométricos inicial (preto) e intermediário (azul).
FIGURA 10 - Radiografias periapicais dos incisivos superiores e inferiores e interproximais dos lados direito e esquerdo intermediárias. 


\section{PLANO DE TRATAMENTO ( ${ }^{\mathrm{a}}$ FASE)}

A segunda fase do tratamento seria iniciada após a exfoliação dos dentes decíduos e a obtenção da relação molar de chave de oclusão. Seguiria-se a instalação de aparelhagem ortodôntica superior e inferior, e arcos 0,014" a 0,018" de aço inoxidável, para alinhamento e nivelamento. Em seguida, arcos retangulares de aço inoxidável 0,019" x 0,026" seriam utilizados para fechamento de espaços residuais, com alças em forma de gota (drop loop) entre incisivos laterais e caninos, se necessário. Para a finalização, seriam utilizados arcos retangulares superior e inferior, também de aço inoxidável 0,019 " x 0,026", com dobras de primeira e terceira ordens, individualizadas de acordo com a necessidade do caso.

A contenção planejada consistia de uma placa superior com grampo do tipo wraparound e, no arco inferior, barra fixa, entre o 33 e o 43 , confeccionada com fio coaxial 0,028" de aço inoxidável.

\section{Progresso do tratamento}

$\mathrm{Na}$ segunda fase do tratamento, iniciou-se a montagem da aparelhagem ortodôntica fixa em ambos os arcos. Foram colados braquetes metálicos do tipo standard, sem torques ou angulações, slot 0,022 " x 0,028", sistema Edgewise, nos prémolares, caninos e incisivos. De maneira sequencial, foram instalados arcos redondos de aço inoxidável para alinhamento e nivelamento $(0,014$ " a 0,018 "). Posteriormente, foram instalados arcos de aço inoxidável 0,019" x 0,026" superior e inferior. No arco superior, os espaços residuais foram administrados para a correção da linha média e, em seguida, foram eliminados com a utilização de elásticos para a realização de tie back, nos lados direito e esquerdo.

Após a fase de finalização ortodôntica e a observação da obtenção dos objetivos planejados, a aparelhagem ortodôntica fixa foi removida para a instalação dos aparelhos de contenção. Foi utilizada uma placa removível, com grampo do tipo wraparound, para o arco superior. No arco inferior, foi instalada uma barra intercaninos fixa, confeccionada com fio coaxial de aço inoxidável 0,028" de secção redonda. Foi recomendada a utilização da placa de contenção superior durante 24 horas por dia, no primeiro ano, e uso noturno após esse período, sem previsão de suspensão.

\section{Resultados obtidos}

Ao final do tratamento, foram solicitados novos exames à paciente. Após avaliação desses, verificouse que os objetivos planejados para o tratamento foram atingidos. Houve redução da discrepância esquelética, no sentido anteroposterior, em 4 graus, tendo o ângulo ANB se modificado de 5 graus para 1 grau. O ângulo SNA foi reduzido em 4 graus, demonstrando a restrição do deslocamento anterior da maxila. O ângulo SNB foi reduzido em 2 graus, na segunda fase do tratamento, provavelmente por remodelação do ponto $\mathrm{B}$, devido ao aumento da inclinação dos incisivos inferiores. Houve bom crescimento anteroposterior da mandíbula, durante a primeira fase de tratamento, sendo quase nulo na segunda fase (Fig. 12, 19).

No aspecto dentário, houve acentuada modificação dos incisivos em ambos os arcos. A inclinação dos incisivos superiores $\left(1-\mathrm{NA}^{\circ}\right)$ foi aumentada em 16 graus e dos inferiores $\left(1-\mathrm{NB}^{\circ}\right)$ em 3 graus (Tab. 1), o que, em parte, explica a redução da sobremordida. Finalizou-se o tratamento com relação de chave de oclusão, nos molares e caninos, bem estabelecida.

Em relação ao aspecto facial, observou-se manutenção dos terços faciais proporcionais e da linha de sorriso. No entanto, devido ao padrão de crescimento inerente à paciente, houve modificação no perfil, ao final da primeira fase de tratamento, deixando-o levemente côncavo (redução da linha $S$ superior e inferior em $3 \mathrm{~mm}$ ).

Nos exames radiográficos panorâmico, periapicais e interproximais, não foram observadas reabsorções radiculares ou comprometimentos periodontais, nem cáries interproximais. Os terceiros molares foram mantidos em acompanhamento (Fig. 15, 16). 

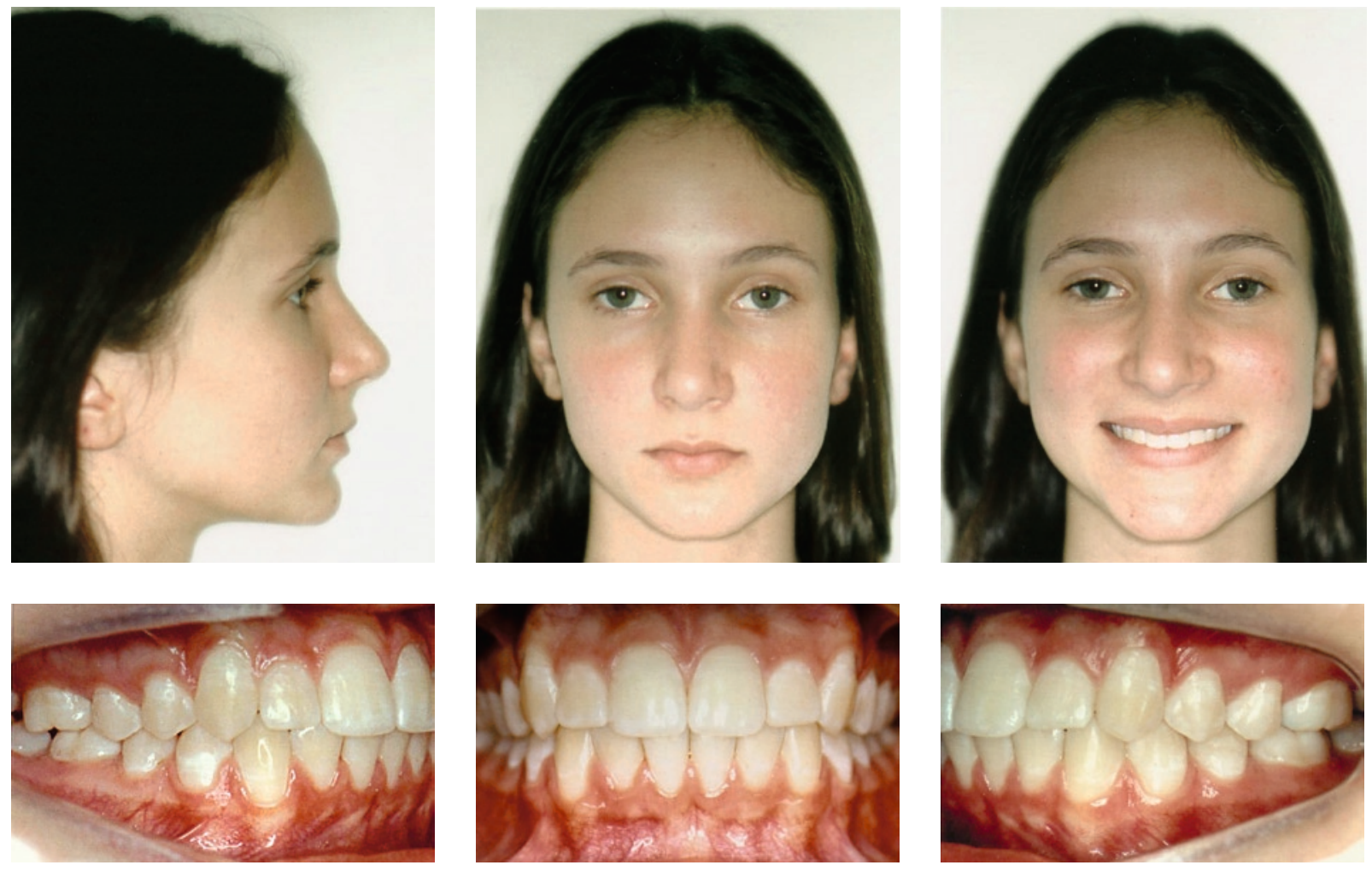

FIGURA 13 - Fotografias faciais e intrabucais finais.
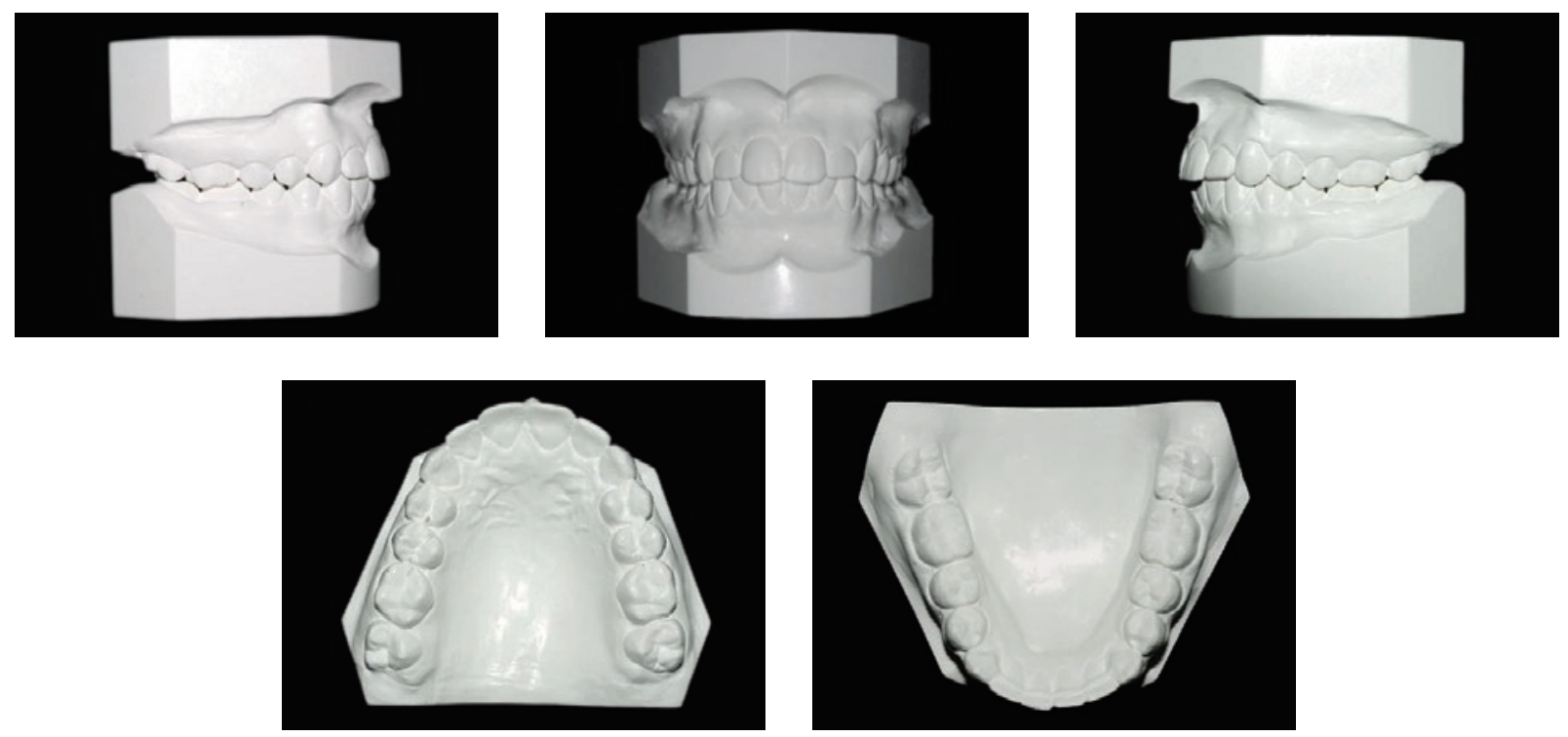

FIGURA 14 - Modelos finais. 


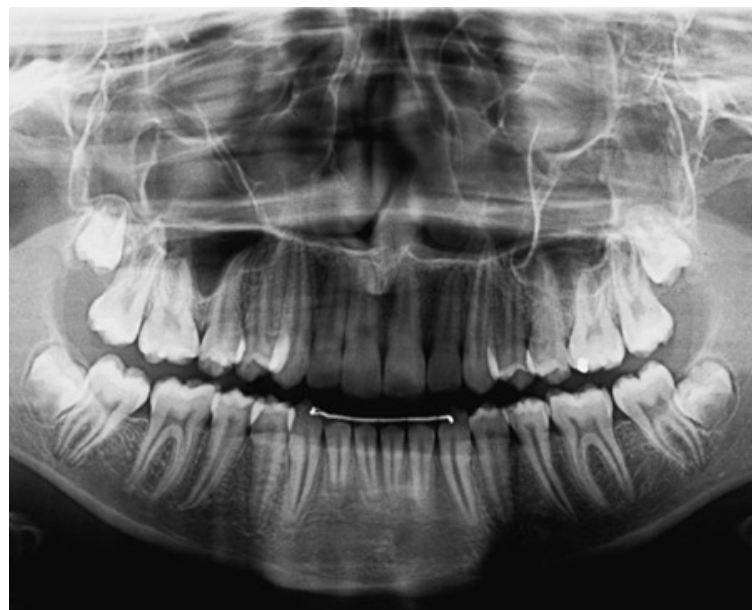

FIGURA 15 - Radiografia panorâmica final.

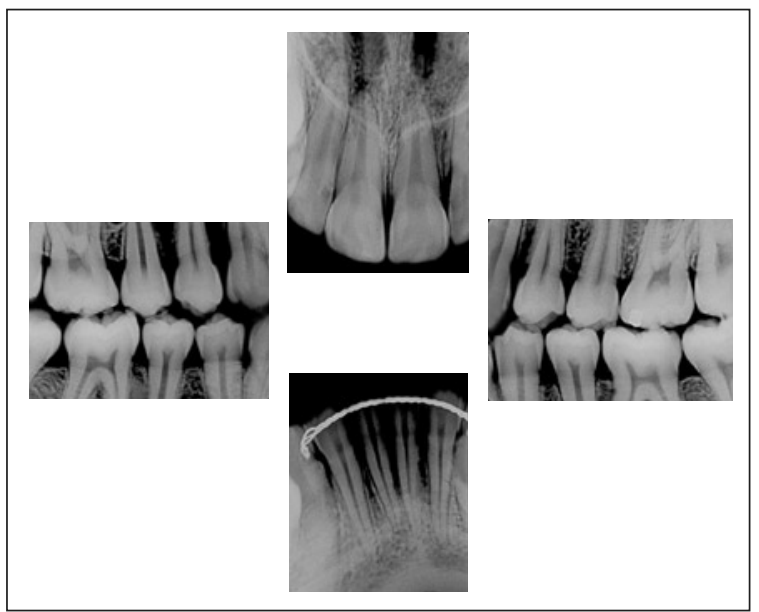

FIGURA 16 - Radiografias periapicais dos incisivos superiores e inferiores e interproximais dos lados direito e esquerdo finais.
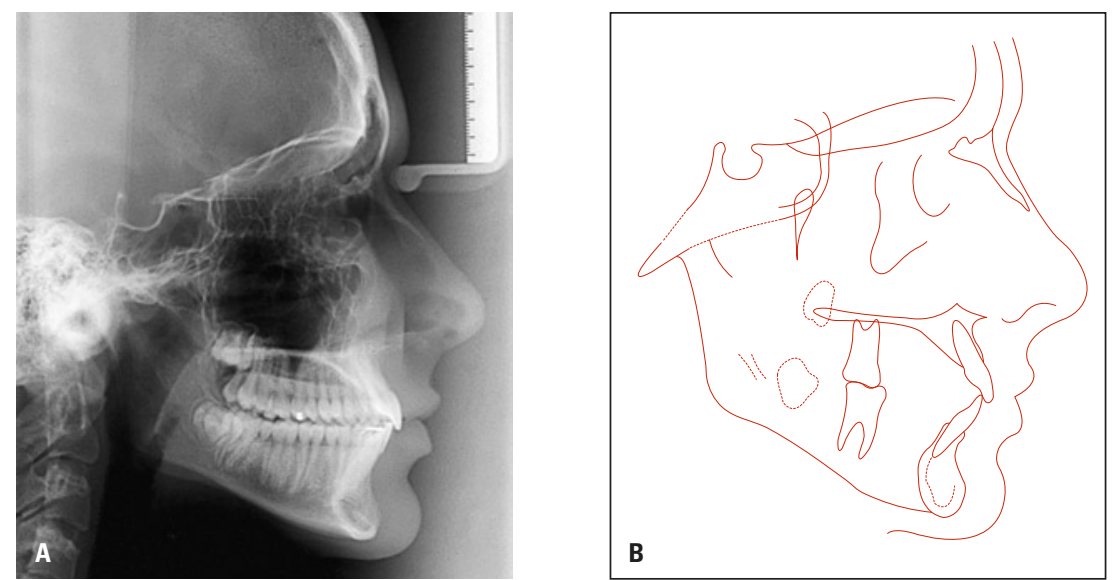

FIGURA 17 - Radiografia cefalométrica de perfil (A) e traçado cefalométrico (B) finais.
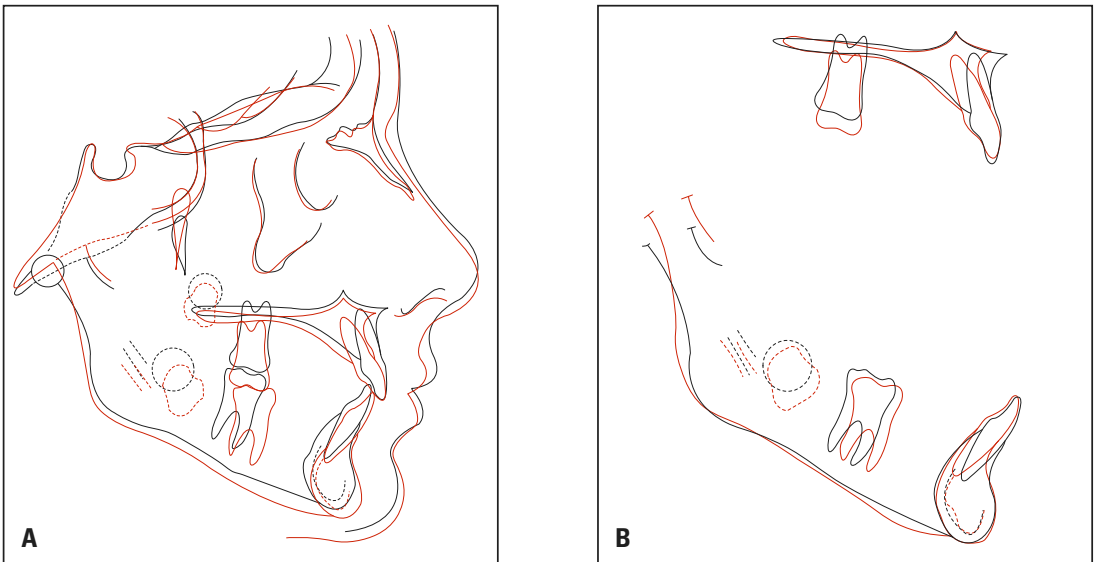

FIGURA 18 - Sobreposições total e parciais dos traçados cefalométricos inicial (preto) e final (vermelho). 

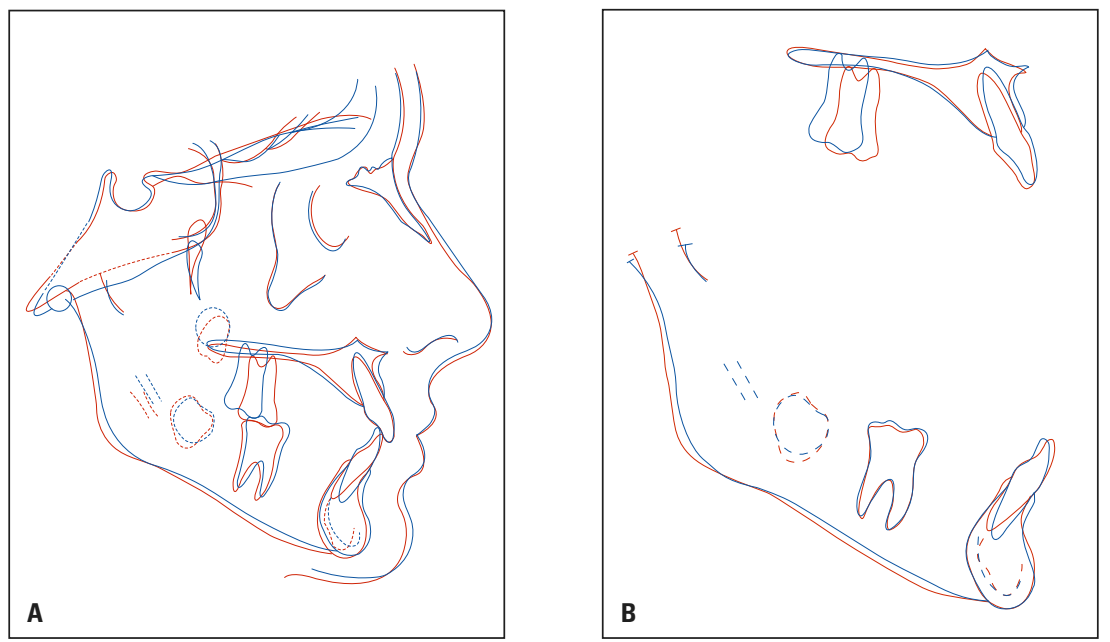

FIGURA 19 - Sobreposições total e parciais dos traçados cefalométricos intermediário (azul) e final (vermelho).

\section{CONSIDERAÇÕES FINAIS}

A má oclusão Classe II de Angle, com sobressaliência acima de $5 \mathrm{~mm}$, ocorre em $23 \%$ das crianças, de acordo com dados epidemiológicos americanos $^{5}$. É, certamente, a má oclusão de maior prevalência e, talvez por isso, existam diversas abordagens terapêuticas sugeridas na literatura, para seu tratamento. Essas podem ser, essencialmente, divididas em três grupos: (a) modificação do crescimento para reduzir a discrepância esquelética; (b) movimento dentário para compensação da discrepância esquelética (camuflagem) e (c) reposicionamento cirúrgico dos ossos maxilares ${ }^{6}$.

Tanto a camuflagem ortodôntica quanto o tratamento ortodôntico-cirúrgico combinado estão relacionados a tratamentos de pacientes que não apresentam mais crescimento. Porém, existe uma enorme variedade de mecanismos para a correção da Classe II, por modificação de crescimento, associado a movimento dentário, que basicamente incluem aparelhos extrabucais ${ }^{2,8}$, aparelhos funcionais $^{5}$ e propulsores mandibulares . $^{4}$

Apesar de terem sido idealizados para tratar a mesma má oclusão, as propostas mecânicas desses aparelhos são diferentes. Os aparelhos extrabucais visam controlar o crescimento da maxila, por uma força anteroposterior, permitindo o crescimento mandibular ${ }^{2,8}$. Os aparelhos funcionais, assim como os propulsores, objetivam estimular o crescimento mandibular através da projeção da mandíbula ${ }^{4,5}$. $\mathrm{Na}$ realidade, por serem aparelhos que se apoiam em dentes, a correção por uma combinação de efeitos ósseo e dentário é inevitável ${ }^{5}$.

Neste caso, optou-se pelo tratamento da Classe II com aparelho extrabucal de Kloehn, em vez de aparelhos funcionais ou propulsores mandibulares, com a intenção de obter o movimento para distal dos molares superiores, assim como o controle do crescimento da maxila, sem incluir os incisivos superiores. Esses dentes já estavam verticalizados $\left(1-\mathrm{NA}^{\circ}=13^{\circ}\right)$ e a pequena sobressaliência inicial dificultaria a utilização de aparelhos funcionais.

Após a publicação de resultados observados em ensaios clínicos randomizados, comparando tratamentos da Classe II em uma ou duas fases, estes se tornaram controversos, principalmente em casos com pequena sobressaliência ${ }^{9}$. No entanto, podemos observar que o crescimento mandibular da paciente ocorreu durante a primeira fase do tratamento (Fig. 12). Durante a segunda fase, não houve crescimento mandibular expressivo (Fig. 19), comprovando a pertinência, neste caso, 

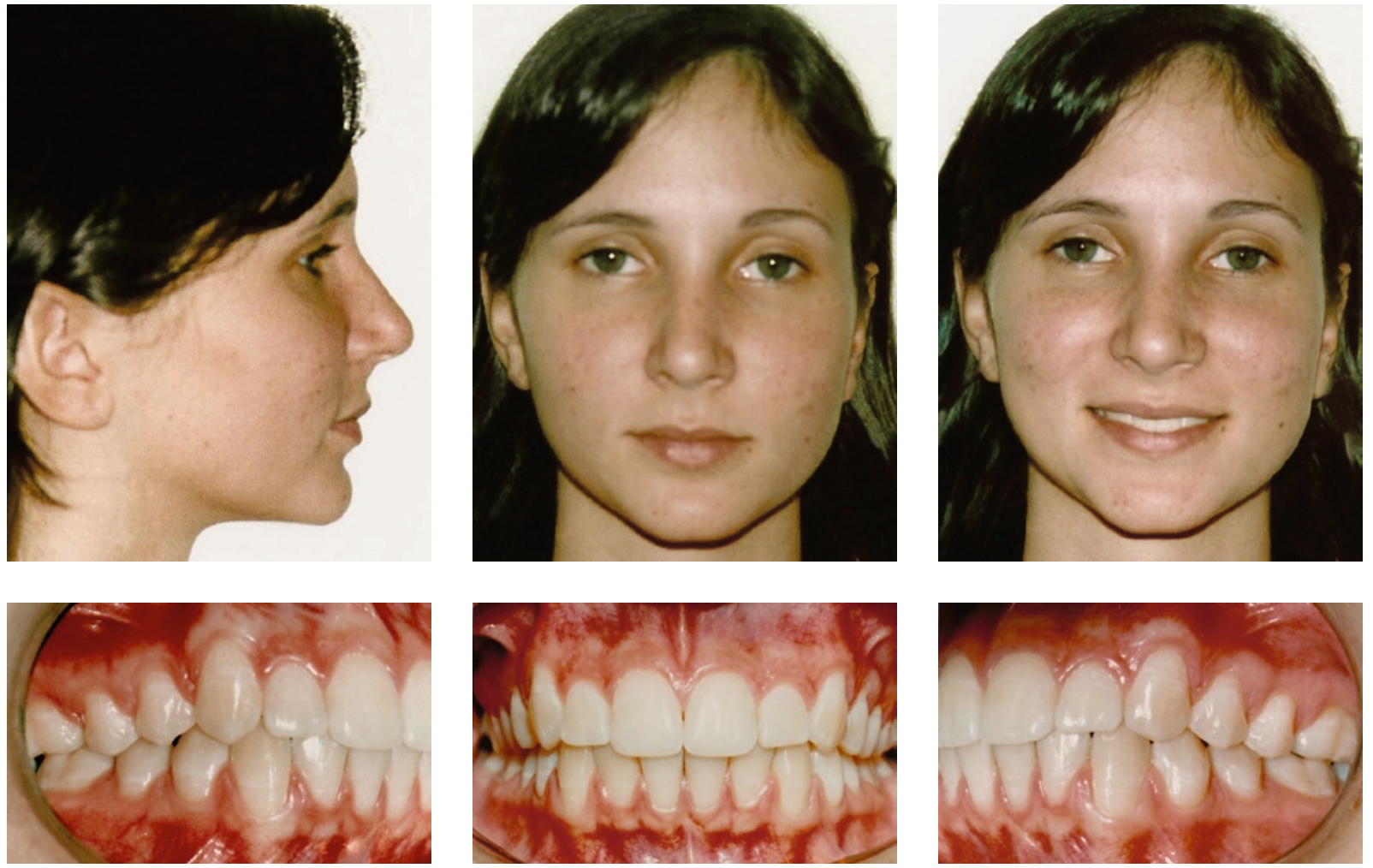

FIGURA 20 - Fotografias faciais e intrabucais de controle cinco anos após o término do tratamento.
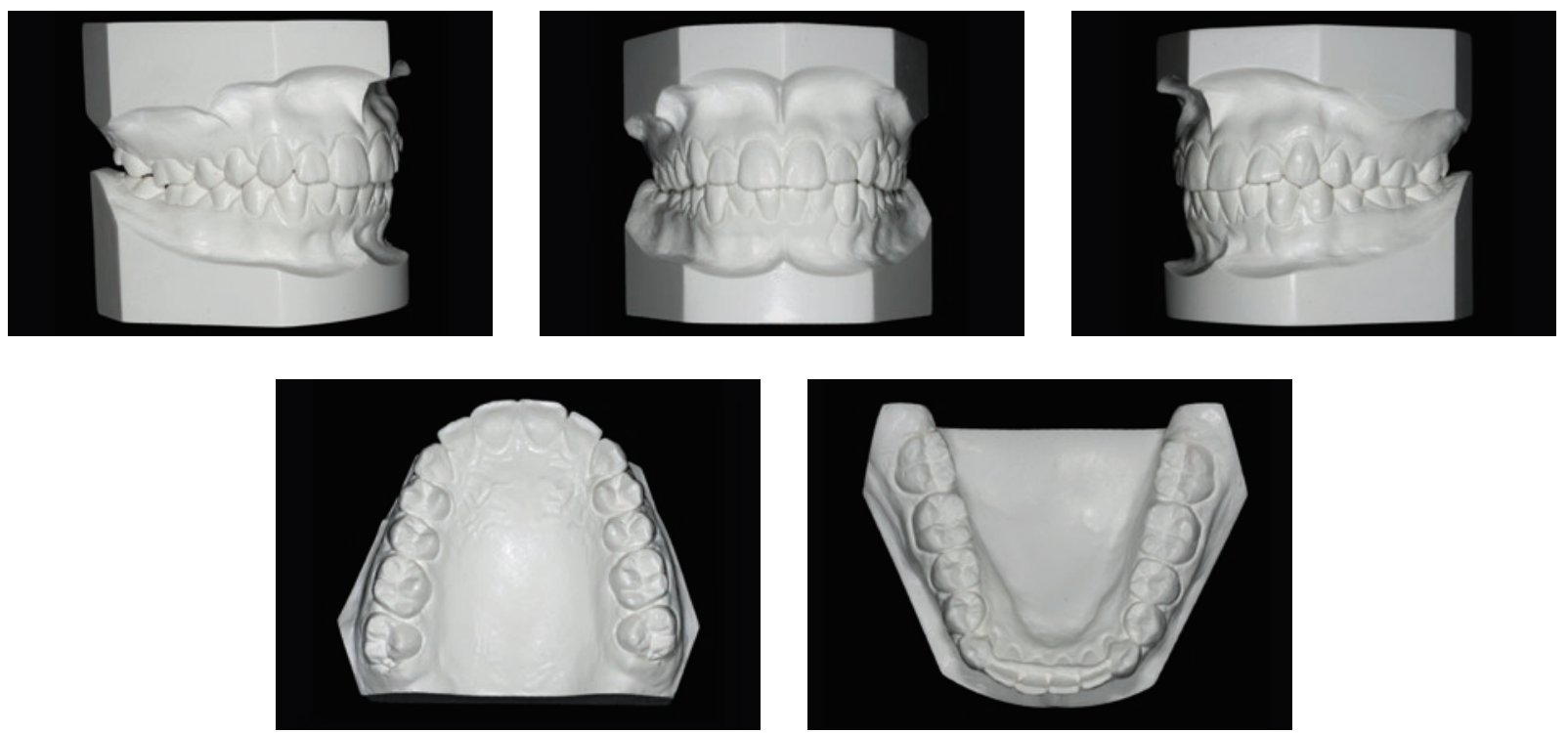

FIGURA 21 - Modelos de controle cinco anos após o término do tratamento. 


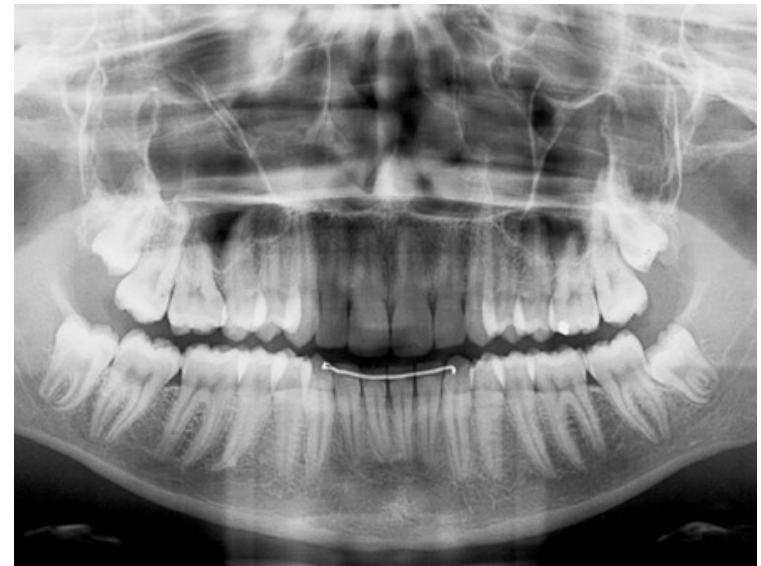

FIGURA 22 - Radiografia panorâmica de controle cinco anos após o término do tratamento.

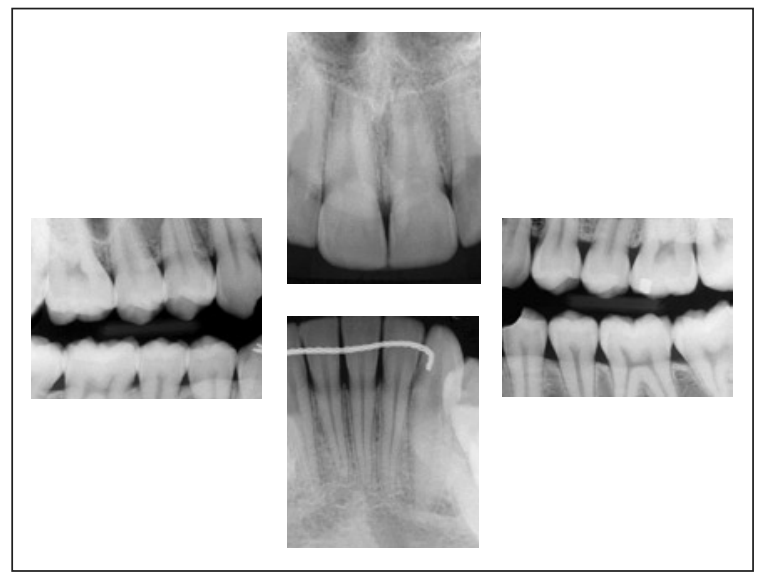

FIGURA 23 - Radiografias periapicais dos incisivos superiores e inferiores e interproximais dos lados direito e esquerdo de controle cinco anos após o término do tratamento.

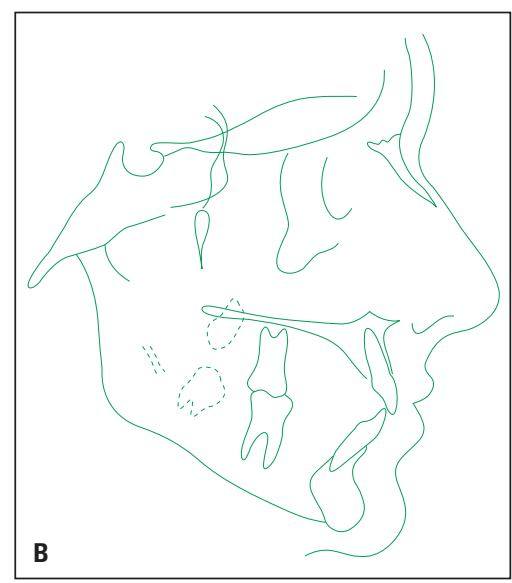

FIGURA 24 - Radiografia cefalométrica de perfil (A) e traçado cefalométrico (B) de controle cinco anos após o término do tratamento.
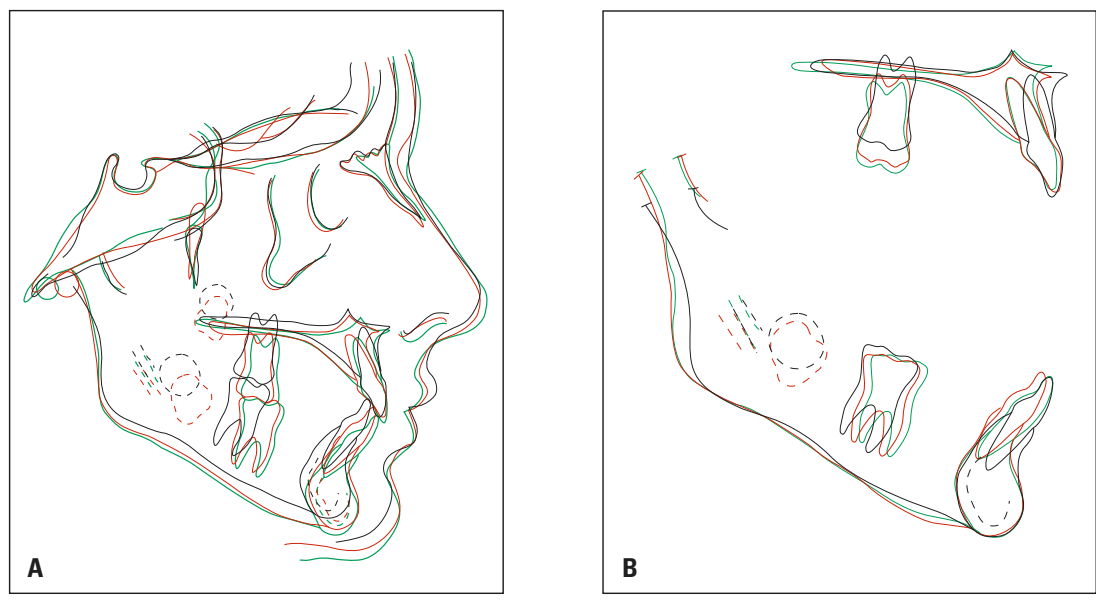

FIGURA 25 - Sobreposições total e parciais dos traçados cefalométricos inicial (preto), final (vermelho) e cinco anos após o término do tratamento (verde). 
TABELA 1 - Resumo das medidas cefalométricas.

\begin{tabular}{|c|c|c|c|c|c|c|c|}
\hline & MEDIDAS & NORMAL & $\mathbf{A}$ & A1 & B & DIFERENÇA A-B & C \\
\hline \multirow{8}{*}{$\begin{array}{c}\text { Padrão } \\
\text { Esquelético }\end{array}$} & SNA (Steiner) & $82^{\circ}$ & $80^{\circ}$ & $78^{\circ}$ & $76^{\circ}$ & 4 & $78^{\circ}$ \\
\hline & SNB (Steiner) & $80^{\circ}$ & $75^{\circ}$ & $77^{\circ}$ & $75^{\circ}$ & 0 & $75^{\circ}$ \\
\hline & ANB (Steiner) & $2^{\circ}$ & $5^{\circ}$ & $1^{\circ}$ & $1^{\circ}$ & 4 & $3^{\circ}$ \\
\hline & Âng. Conv. (Downs) & $0^{\circ}$ & $8^{\circ}$ & $-2^{\circ}$ & $-3^{0}$ & 11 & $1^{\circ}$ \\
\hline & Eixo Y (Downs) & $59^{\circ}$ & $57^{\circ}$ & $57^{\circ}$ & $59^{\circ}$ & 2 & $58^{\circ}$ \\
\hline & Âng. Facial (Downs) & $87^{\circ}$ & $84^{\circ}$ & $87^{\circ}$ & $86^{\circ}$ & 2 & $87^{\circ}$ \\
\hline & SN-GoGn (Steiner) & $32^{\circ}$ & $32^{\circ}$ & $32^{\circ}$ & $31^{\circ}$ & 1 & $32^{\circ}$ \\
\hline & FMA (Tweed) & $25^{\circ}$ & $27^{\circ}$ & $26^{\circ}$ & $27^{\circ}$ & 0 & $27^{\circ}$ \\
\hline \multirow{7}{*}{$\begin{array}{c}\text { Padrão } \\
\text { Dentário }\end{array}$} & IMPA (Tweed) & $90^{\circ}$ & $98^{\circ}$ & $91^{\circ}$ & $100^{\circ}$ & 2 & $104^{\circ}$ \\
\hline & 1-NA ${ }^{\circ}$ (Steiner) & $22^{\circ}$ & $13^{\circ}$ & $25^{\circ}$ & $29^{\circ}$ & 16 & $20^{\circ}$ \\
\hline & 1-NA mm (Steiner) & $4 \mathrm{~mm}$ & $3 \mathrm{~mm}$ & $5 \mathrm{~mm}$ & $7 \mathrm{~mm}$ & 4 & $5 \mathrm{~mm}$ \\
\hline & 1-NB ${ }^{\circ}$ (Steiner) & $25^{\circ}$ & $28^{\circ}$ & $22^{\circ}$ & $31^{\circ}$ & 3 & $35^{\circ}$ \\
\hline & 1-NB mm (Steiner) & $4 \mathrm{~mm}$ & $5 \mathrm{~mm}$ & $3 \mathrm{~mm}$ & $6 \mathrm{~mm}$ & 1 & $7 \mathrm{~mm}$ \\
\hline & Âng. Interincisal (Downs) & $130^{\circ}$ & $134^{\circ}$ & $132^{\circ}$ & $119^{\circ}$ & 15 & $121^{\circ}$ \\
\hline & 1-APo mm (Ricketts) & $1 \mathrm{~mm}$ & $3 \mathrm{~mm}$ & $1 \mathrm{~mm}$ & $4 \mathrm{~mm}$ & 1 & $3 \mathrm{~mm}$ \\
\hline \multirow{2}{*}{ Perfil } & L.Sup - Linha S (Steiner) & $0 \mathrm{~mm}$ & $1 \mathrm{~mm}$ & $-2 m m$ & $-2 m m$ & -3 & $-4 m m$ \\
\hline & L.Inf - Linha S (Steiner) & $0 \mathrm{~mm}$ & $1 \mathrm{~mm}$ & $-2 m m$ & $-2 m m$ & -3 & $-3 m m$ \\
\hline
\end{tabular}

de um tratamento em duas etapas.

Houve preocupação com o envelhecimento da face, uma vez que o tempo vem sendo considerado como fator influente no plano de tratamento $^{7}$. De acordo com estudos de estabilidade dos arcos dentários, há poucas garantias de manutenção do comprimento do arco ao longo da vida, mesmo em casos submetidos a extrações de pré-molares ${ }^{3}$. Portanto, foi estabelecida contenção fixa no arco inferior, por tempo indeterminado. Os exames obtidos para avaliação de controle pós-tratamento demonstram a boa estabilidade do caso (Fig. 20 - 24). Os terceiros molares não foram removidos, por apresentarem grande possibilidade de irrupção ${ }^{1}$. A paciente continuou sendo acompanhada após o tratamento e observouse melhora do posicionamento dos mesmos.

As pequenas modificações dentárias realizadas, neste tratamento, advêm de um bom diagnóstico, permitindo a escolha adequada e, principalmente, estável. A primeira fase, iniciada em idade acertada, possibilitou o aproveitamento do crescimento, tornando o tratamento ortodôntico, na segunda fase, mais simples e exigindo menor colaboração da paciente. A sobremordida foi corrigida e mantida estável, assim como as relações oclusais no sentido anteroposterior. 


\title{
Angle Class II malocclusion treated without extractions and with growth control
}

\begin{abstract}
Angle Class II malocclusion is characterized by an anteroposterior dental discrepancy which is generally accompanied by skeletal disharmonies. Early orthodontic treatment allows the correction of skeletal discrepancies using growth control (first phase) which favors later correction of tooth positioning (second phase). This case report describes an Angle Class II, division 2, malocclusion treated in two phases and was presented to the Brazilian Board of Orthodontics and Facial Orthopedics (BBO) as part of the requirements for BBO certification. It was evaluated as a Category 1 case, i.e., Class II malocclusion treated without extractions, with growth control.
\end{abstract}

Keywords: Angle Class II malocclusion. Interceptive Orthodontics. Corrective Orthodontics.

\section{REFERÊNCIAS}

1. ARTESE, F. Pergunte a um Expert. Rev. Clin. Ortodon. Dental Press, Maringá, v. 5, p. 14-23, 2006.

2. KLOEHN, S. J. Evaluation of cervical anchorage force in treatment. Angle Orthod., Appleton, v. 31, no. 2, p. 91-104, Apr. 1961.

3. LITTLE, R. M. Stability and relapse of mandibular anterior alignment: University of Washington studies. Semin. Orthod., Philadelphia, v. 5, no. 3, p. 191-204, Sept. 1999.

4. PANCHERZ, H. The Herbst appliance: a paradigm change in Class II treatment. World J. Orthod., Carol Stream, v. 6, p. 8-10, 2005. Supplement.

5. PROFFIT, W. R.; FIELDS, H. W. Contemporary Orthodontics. 3rd ed. St. Louis: C. V. Mosby, 1999.

6. PROFFIT, W. R.; PHILLIPS, C.; DOUVARTZIDIS, N. A

comparison of outcomes of orthodontic and surgical-

orthodontic treatment of Class II malocclusion in adults. Am.

J. Orthod. Dentofacial Orthop., St. Louis, v. 101, p. 556-565,

1992.
7. SARVER, D. M.; ACKERMAN, M. B. Dynamic smile visualization and quantification: part 2. Smile analysis and treatment strategies. Am. J. Orthod. Dentofacial Orthop., St. Louis, v. 124, no. 2, p. 116-127, Aug. 2003.

8. THUROW, R. C. Craniomaxillary orthopedic correction with en masse dental control. Am. J. Orthod., St. Louis, v. 68, no. 6, p. 601-624, Dec. 1975.

9. TULLOCH, J. F.; PROFFIT, W. R.; PHILLIPS, C. Outcomes in a 2-phase randomized clinical trial of early Class II treatment. Am. J. Orthod. Dentofacial Orthop., St. Louis, v. 125, no. 6, p. 657-667, June 2004.
Endereço para correspondência

Flávia Artese

Rua Santa Clara, 75/1110 - Copacabana

CEP: 22.041-010 - Rio de Janeiro / RJ

E-mail: flaviaartese@gmail.com 